\title{
Educating to the Scientific Method and Culture in the Italian University Museums
}

\author{
Elena Corradini \\ Department of Engineering "Enzo Ferrari", University of Modena and Reggio Emilia, Italy
}

Received April 6, 2020; Revised August 3, 2020; Accepted August 7, 2020

\section{Cite This Paper in the following Citation Styles}

(a): [1] Elena Corradini , "Educating to the scientific Method and Culture in the Italian University Museums, "Universal Journal of Educational Research, Vol. 8, No. 10, pp. 4891 - 4896, 2020. DOI: 10.13189/ujer.2020.081061.

(b): Elena Corradini (2020). Educating to the scientific Method and Culture in the Italian University Museums. Universal Journal of Educational Research, 8(10), 4891 - 4896. DOI: 10.13189/ujer.2020.081061.

Copyright $\mathrm{C} 2020$ by authors, all rights reserved. Authors agree that this article remains permanently open access under the terms of the Creative Commons Attribution License 4.0 International License

\begin{abstract}
The first Italian University Museums Network, constituted in 2012 for a first project, coordinated by Modena and Reggio Emilia, in 2015 started a second project, approved and financed by the Ministry of the University and Research (Online available from http://www.pomui.unimore.it), dedicated to orient the students to the scientific method and culture. The primary objective was to promote, starting from the historical-scientific and naturalistic heritage of the Network, among the students of the IV and V High School classes, the interest in scientific culture that still suffers not only in our country but worldwide. The Museums of the Network decided not only to propose to look at their scientific instruments and naturalistic specimens or to observe the reproduction of some natural phenomena, but with a hands-on approach for raising awareness, to provide to the students the tools in order to understand the cultural context in which the scientific instruments have been invented or realized, the specimens collected, the phenomena observed for the first time. The museums realized 56 experiential educational paths through the individuation and the sharing of operative methods, the adoption and the use of common languages and tools, with specific attention to the information technologies. These paths are dedicated to three principal themes, biodiversity, color and time, and seven subthemes and are published in the Network web portal (Online available from http://www.retemuseiuniversitari.unimore.it). After this experience, an University Museums Observatory will be useful to help the University Museums to become privileged places of the science communication, laboratories of participation, observatories on the past,
\end{abstract}

present and future and able to promote and develop students' interests and skills for the scientific culture.

Keywords Scientific Education, Scientific Method, Italian University Museums Network

\section{Introduction: The First and the Second Project of the Italian University Museums Network}

The collections of the University Museums testify the historical development of scientific researches in different disciplines: the several collections are archives of knowledge, built during the centuries, that need a dynamic informative and articulated dimension through the use of new information technologies. These considerations were the fundamental starting point for the creation, in 2012, of the first Network of Italian University Museums among 12 Universities (Bari, Cagliari, Chieti-Pescara, Ferrara, Florence, Modena and Reggio Emilia, Parma, Perugia, Rome "La Sapienza", Salento, Siena, Tuscia, with the Regional Museum of Natural Sciences of Turin) with the coordination of the University of Modena and Reggio Emilia. The objective of the Network was the valorization of their collections, through the use of the information technologies, in a web portal, thanks to a project approved and financed by the Ministry of the University and Research (Online available from http://www.pomui.unimore.it) [1]. In this Network web portal, the most important collections of 64 University 
Museums, 38 collections and 9 botanical gardens are being enhanced, through their contextualization, in the ambit of 80 cultural paths dedicated to four themes [2]: 19 to the landscapes, 18 to the environments, 4 to the stories, 9 to the histories of scientific instrumentation, considered important for the interest that they can arouse in wide ranges of the audience, linking them to the history of the research (Online available from http://www.retemuseiuniversitari.unimore.it) [3].

Each path is organized into four sections: the introductive section is followed by the other three ones. In the first one, dedicated to the exploration of the collections, the pictures and descriptions of the specimens are provided by a lot of catalogue cards, different for each discipline [4], managed through the standard of the Central Institute for Cataloging and Documentation (Online available from http://www.iccd.beniculturali.it/) of the Ministry of Cultural Heritage and Tourism through the SIGECweb, Informative System for the General Catalogue of the Cultural Heritage. In the second section, dedicated to the visit of the museum, the specimens and instruments are contextualized in the ambit of the museum to which they belong [5]. In the third section, they are linked to the territory of reference to stimulate the public to discover his peculiarity, to plan a visit, and to encourage conscious cultural tourism [6].

After the positive experience of this project, the Museums of the Network have become more aware of the importance of the work in synergy to be relevant centers of production of activities and services for the diffusion of the scientific knowledge through the individuation and the sharing of operative methods, the adoption and the use of common languages and tools, with specific attention to the information technologies [7]. In 2015 the Network (to which the Universities of Genova and Pavia and the Civic Museums of Reggio Emilia have been added), with the coordination of the University of Modena and Reggio Emilia, started a second project, approved and financed by the Ministry of the University and Research (Online available from www.pomui.unimore.it). The project was finalized to the realization of experiential educational paths dedicated to the orientation to the scientific method and culture. Starting from the historical-scientific and naturalistic heritage of the Museums of the Network, the primary objective of these paths was to promote, among the students of the IV and V High School classes, interest in scientific culture that still suffers not only in our Country but worldwide (Online available from http://www.oecd.org/pisa/keyfindings/pisa-2012-results-o verview.pdf) [8]. The still deficient diffusion of scientific culture has significant effects on the orientation of High School students towards their succeeding higher education as well as other essential life choices and the number of graduates in scientific disciplines, with respect to the whole of graduates, is decreasing. For this reason the specific action line of this project, in accordance with one of the fundamental strategic objectives of the Italian Universities, was the orientation of the students to the scientific culture, helping them to "develop their identity, to take decisions on their personal and professional life" as requested by the Guidelines for the permanent Orientation published by the Ministry of the University and Research in 2014 (Online available from: http://www.istruzione.it/orientamento), in connection with the Orientation Services of the different Universities.

A resolution of the Council of Europe (n. 15030 del 2008 - EDUC 257, SOC 653 (Online available from https://register.consilium.europa.eu/doc/srv?l=EN\&f=ST $\% 2015030 \% 202008 \% 20$ INIT) indicates that the permanent orientation has to be more integrated into the strategies of permanent learning. Good orientation can be provided by the University Museums, not only as cultural structures but also as places of advanced and laboratory teaching, so to give a solid support to the orientation during critical phases of the school experience.

\section{Materials and Methods}

Through the experiential educational paths realized for this project, the museums of the Network wanted to recover the relationship with the real and concrete objects or specimens of the museum's collections and the researches developed over the time through them, in order to stimulate the student's interest in the scientific method, retracing the historical path of the evolution of the different disciplines from the eighteenth century. The educational paths realized by and within the University Museums with elementary experiments will fit, on the one side, into the school education (still generalist) and, on the other side, into the University education (highly specialist, experimental and technically advanced) in order to transmit that unifying component, common to the different disciplinary fields, that is represented by the scientific method. The fundamental steps are three: a) comprehension of the reasons that brought to the formation and preservation of the scientific collections as well as of their being archives of knowledge built up during the centuries; $b$ ) praxis of simple experimental activities, laboratories and stages within the fascinating context of the museums; c) development of a path from and back to school, through the working out of brief essays (both individual or collective) that meet the requirements of the experimental approach, in particular the rigorousness of method, the control and reproducibility of experiments, the distinction between results and inferences. From the modalities of achievement and from the method and articulation of the path, it is clear that the choice has been the one of the experiential learning [9] which can be referred to the four-step model of Kolb's theory [10] that provides for: 1) concrete experience phase through the direct vision of the museum's objects and the experience of laboratory, in which learning is influenced 
by perceptions and reactions to experiences; 2) reflective observation phase, in which learning is influenced by listening and observation; 3) abstract conceptualization in which learning takes shape from the systematic thought and analysis of problems; 4) active experimentation phase, in which learning is influenced by acting, experimenting and observing the results obtained at the end of the educational path.

The basic idea of Kolb's learning style theory is that not every person learns in the same way, but that everybody had a preferred learning style (or sometimes a combination of two or a combination of four): the dreamer learning style emphasizes concrete experience and reflective observation; for the deliberator the dominant learning abilities are abstract conceptualization and reflective observation; the decider relies primarily on the dominant learning abilities abstract conceptualization and active experimentation; the doer emphasizes concrete experience and active experimentation. Considering these four learning styles which dedermine how a student undertakes his learning process, the Museums of the Networks (62 museums, 54 collections e 12 botanical gardens), have tried to redraw the educational function of the cultural scientific heritage in the key of a bigger systematic approach, configuring the dialogue modalities on the base of criteria of interoperability. The adoption of common themes and narratives has experimented with their capacity to formulate contents and ways of communications that, integrating different languages, want to be effective because simple and clear, without losing scientific rigorousness and adequacy. The Museums decided to consider three aspects that could determine the effect of the educational paths that they have to organize: content and information supply, the attitude of the student, the atmosphere, and design. For content and information supply the difference between the learning styles is particularly determined by the understand-experience dimension. Understanding is connected with factual argumentation (abstract, symbolic, analytical and verbal) and the experience with the evocation of an experience (concrete, versatile and spatial). For contents and information supply, the dreamer and the doer will, for instance, be more interested in subjective information while the decider and the deliberator will more focus on objective information. The attitude of the student can be determined by the external-internal dimension. This relates especially to the way in which the information and the experience are digested. External is outside oriented. The presentation is actively approached and used to do something with it and to reach personal aims. Internal, on the other hand, is focused inwardly. The educational path is observed and perceived, through direct experience, and the student's interpretation plays an important role here. While the dreamer and deliberator will, for instance, be interested in what is the truth, the decider and the doer will search for the best solution. Atmosphere and design is a combination of attitude on the one hand and of content and information supply on the other. In starting from experience, combined with external (the doer) hands-on activities are conceivable in which the personal experience comes first. In the combination experience/internal (the dreamer), it is more a case of a personal experience which may respond to, for instance, atmospheric presentation in which the context can be determined by a student's personal experience. Understanding combined with external (the decider) also requires hands-on activities but in that case focused on technical style side, when a theory can be tried out in practice. In the combination understanding/internal (the deliberator), factual information is important as in this analysis of this information.

After an articulated and constructive debate, the Museums staff chose three general themes, biodiversity, color and time, that, articulated in seven subthemes (color in nature, in art and science, in physics; the measurement of time, geology and fossils, the evolution of man and the evolution of Antarctica). The themes and subthemes would permit to realize effective experiential educational paths to let students know the history of the formation of the museum collections, making them aware of their value of archives of knowledge collected over the time, and to practice simple experimental activities of laboratory and internship in the suggestive context of the museums with the support of the young cultural mediators, specially trained by the persons in charge of the museums to follow the realization of this project. Every path should have started at school, in consideration of the in-depth study materials (texts, images and videos) published in the first section of the web portal of the Network, and found foundation in the experiences of every museum, in the potentiality of every single collection and in the synergy already activated from sharing the network work carried out for the first project (Online available from: https://www.retemuseiuniversitari.unimore.it).

\section{Results}

All the 56 experiential educational paths of non-formal education, dedicated to the three thematic areas, biodiversity and agrobiodiversity, color and time [11], realized for the project, are published in the second section of the web portal of the Network. In these three thematic areas, graphically represented through a conceptual map, created to summarize the process of developing the theme, 9 paths are dedicated to biodiversity and agrobiodiversity, the others 47 to the color and to the time. These are divided into the seven sub-themes represented by seven conceptual maps. For the color 9 paths have been dedicated to the color in nature, 7 to the color in art and science, 4 to the color in physics. For the time 10 pats have been dedicated to the Geology and the fossils, 6 to the measurement of the time, 9 to the evolution of the man, 2 to the evolution of 
Antarctica (Online available from: https://www.retemuseiuniversitari.unimore.it) [12].

In the various educational paths, the common sub-theme is treated with diversified insights thanks to the active collaboration between the persons in charge of the museums and some young cultural mediators which have been provided with specific training for this project [13]. All the paths have been characterized by the use of real objects, instruments, or specimens in the various proposed activities for which experiences of direct scientific observation but also other cultural practices of readings and storytelling were capable of allowing the approach to the experimental method [14].

Each educational path is articulated with a general objective, specific objectives and methods of achievement, where it is specified from which question the experimentation starts. These are followed by the research and the experimentation that is conducted in the museum and the laboratory, by the final data of the experience and by the story of its sharing [15]. The articulation of each path is described in all its phases and with the graphic, photographic, or multimedia documents created during the experience [16]. For each path, a general and a specific bibliography, videos, images are available on the portal for both students and teachers, for whom the use of information technology is essential thanks to the variety of multimedia support. In another sector of each path, a final report has been included, accompanied by any kind of documents produced by the students (texts, images, videos, websites) to facilitate their sharing, dissemination, and verification of the results [17].

\section{Discussion}

The opportunity of a bigger integration of the education to the cultural heritage in the school curricula was highlighted in the "Recommendation of the Committee of Ministers to member States on the European Cultural Heritage Strategy for the 21st century (Adopted by the Committee of Ministers on 22 February 2017 at the 1278th meeting of the Ministers' Deputies)" (Online available from:

https://www.coe.int/en/web/culture-and-heritage/strategy21), where concerning the "knowledge and education", it is specified that "focuses on the relationship between heritage and shared knowledge, covering awareness raising, training and research helping to foster a shared knowledge society identifying, preserving, transmitting and sharing heritage knowledge and skills". Also in the following Decision 864 of the European Parliament and of the Council dated 17 May 2017 related to the European year of Cultural Heritage (2018) (Online available from: https://eur-lex.europa.eu/legal-content/EN/TXT/?uri=CEL EX\%3A32017D0864), it was reconfirmed the necessity to promote bigger access to the cultural heritage and among the others objectives it was indicated the one of "supporting the development of specialized skills and improve knowledge management and knowledge transfer in the cultural heritage sector, taking into account the implications of the digital skills". The University Museums decided not only to propose to look at the scientific instruments and naturalistic specimens or to observe the reproduction of a natural phenomenon but with a hands-on approach for raising awareness, to provide to the students the tools in order to understand the cultural context in which the scientific instruments have been invented or realized, the specimens collected, the phenomenon observed for the first time. They take the opportunity to promote and develop interests and skills of the students through interaction with the collections, through the practice exploration, experimentation, stimulating their curiosity and imagination, the sensory faculties beyond those cognitive.

\section{Conclusions}

An online questionnaire for the students has been prepared to verify the efficacy of the new experiential forms of learning proposed by the educational paths realized by the University Museums of the Network. The questionnaire is also a useful instrument to verify the learning attitude of each student, according to Kolb's characteristics of the learning styles (the dreamer, the deliberator, the decider, the doer) and it can help the teachers to better know their students. The questionnaire is composed of ten questions; the first 4 are common to all students. The purpose is to verify if each path was useful to increase their global competences, i.e. if the used method was efficient to communicate to students the scientific notions regarding the selected theme, to solicit them to learn new things, to stimulate their creativity and moreover their interest for scientific studies. The other six questions are dedicated to the understanding of the subthemes to which the path is dedicated and are common to all the paths dedicated to the same subtheme; the last 3 questions have been formulated to verify the interest aroused in students by active participation in the educative path.

The answers collected have given good results concerning the understanding of the subthemes and the interest aroused by the modality of execution of the paths, by the specificity of the topics and by the laboratory experiences, but remains doubts on the capability to stimulate an effective interest of students in-depth scientific studies for the continuation of their school career, in particular the University one, that need, in particular, a bigger synergy between the Orientation Offices of the Universities.

With this project, the Italian University Museums Network wanted to propose an educational/formative strategy for the scientific museums promoting structured 
paths for the students that interact with the use of updated multimedia products and informatics devices.

From the results that we have collected yet and from the discussions among professors, persons in charge, curators of University Museums and cultural mediators have emerged the will to consolidate the action lines to redraw the educational function of the scientific museums in the key of a bigger systematic approach, innovating ambits and procedures, configuring the dialogue modalities and the plurality of actors on the base of interoperability criteria, adoption of common themes and narrations, as suggested by the recent National Plan for Education to Cultural Heritage of the Directorate-General for Education, Research and Cultural Institutes of the Ministry of Cultural Heritage and Tourism (Online available from: https://dger.beniculturali.it/educazione/piano-nazionale-pe r-leducazione-al-patrimonio/).

To coordinate the activities of the University Museums, with specific attention to educational activities, it will be useful for the creation of an Observatory for the Italian University Museums. The first step can be an agreement recently entered into between the CRUI (Conference of Italian University Deans) (Online available from: https://www.crui.it/) and the Directorate-General for Education, Research and Culture Institutes of the Ministry of Cultural Heritage and Tourism. Moreover fundamental is the collaboration with national and international institutions, associations devoted to heritage education, in particular with the CECA, International Committee for Education and Cultural Action (Online available from: http://ceca.mini.icom.museum/welcome/ ) of the ICOM (International Council of Museums), for the specific role that it played in the field of museum education [18].

\section{REFERENCES}

[1] E. Corradini, POMUI. The web portal of Italian University Museums, N. Nyst, P. Stambury, C. Weber, (edited by), Proceedings of the 10th Conference of the International Committee of ICOM for University Museums and Collections (UMAC), University Museums and Collections as Recorders of Cultural and Natural Communities Worldwide, Shanghai, November 7-12, 2010, University Museums and Collections Journal, 4, 77-84, 2011.

[2] E. Corradini, The new communication technologies for sharing and participatory Italian University Museums, N. Nyst, P. Stanbury, C. Weber (edited by), Proceedings of the 11th Conference of the International Committee of ICOM for University Museums and Collections (UMAC), University collections and University history and identity, Lisbon, September 21-25, 2011, University Museums and Collections Journal, 5, 133-146, 2012.

[3] E. Corradini, L. Campanella, The multimedia technologies and the new realities for knowledge networking and valorisation of scientific cultural heritage. The role of the Italian University Museums network, L. Marchegiani (edited by), Proceedings of the International Conference on Sustainable Cultural Heritage Management, Roma, Aracne, 283-297, 2013.

[4] E. Corradini, La catalogazione e nuove tecnologie informatiche per l'accessibilità al patrimonio naturalistico, $\mathrm{S}$. Mazzotta, G. Malerba (edited by), Memorie del XX Congresso ANMS - Associazione Nazionale Musei Scientifici, I musei delle scienze e la biodiversità, Ferrara 17-19 novembre 2010, Museologia Scientifica Memorie, 9, 33-39, 2013.

[5] E. Corradini, L. Campanella, A national project for the Italian University Museums network, N. Nyst, P. Stanbury, C. Weber (edited by), Proceedings of the 13th Conference of the International Committee of ICOM for University Museums and Collections (UMAC), Evaluating change The University Museum, Rio de Janeiro, August 10-17, 2013, University Museums and Collections Journal, 7, 20-29, 2014.

[6] E. Corradini, L. Campanella, Digital technologies for the first network of the Italian University Museums, Annual Conference CIDOC - Comité International pour la Documentation, Access and Understanding - Networking in the Digital Era, Dresden, September 6-11, 2014, Conference Paper, 42-49, 2014 (Online available from: http://network.icom.museum/cidoc/archive/past-conference s/2014-dresden/.

[7] K. Keramidas, Interactive development as pedagogical process: digital media design in the classroom as a method for recontextualizing the study of material culture", N. Proctor, R. Cherry, Museum \& the Web - Selected Papers from Two International Conferences. USA: Museum and the Web LLC, 260-27, 2014.

[8] L. Kelly, S. Groundwter Smith, "Revisioning the Physical and On-line Museum: A Partnership with the Coalition of Knowledge Building Schools", Journal of Museum Education, 34(4), 55-68, 2009; L. Kelly, P. Fitzgerald, Cooperation, collaboration, challenge: how to work with the changing nature of educational audiences in museums, $\mathrm{N}$. Mockler, J. Sachs, Rethinking Educational Practice Through Reflexive Inquiry. London: Springer, 77-88, 2011; L. Kelly, Learning in 140 Characters: the future of Museum Learning in a Digital Age, N. Proctor, R. Cherry, Museum \& the Web - Selected Papers from Two International Conferences. USA, in Museum and the Web LLC, 63-72, 2014; T. Seligmann, Learning Museum. A Meeting Place for Pre-Service Teachers and Museums, Journal of Museum Education, 39(1), 42-53, 2014.

[9] A. Cadamuro, Stili cognitivi e stili di apprendimento. Da quello che pensi a come lo pensi, Roma: Carocci Editore, 2006.

[10] D. A. Kolb, Experiential learning: Experience as the source of learning and development, Englewood Cliffs, NJ: Prentice-Hall, 1984; F. Hoogstraat, V. Heijn, Leersstijlen von Kolb in het museum: dromer, denker, beslisser, doener, Amsterdam:Museumvereniging, 2006; J. H. Falk, 1. j. Dierking, The Museum experiencerevisited, Oxford, Routledge, 2012; Best practice 6. A tool to improve museum education internationally, Roma: Centro Stampa Nuova Cultura, 2017.

[11] M. Standley, Digital Storytelling: using new technology and the power of stories to help our students learn- and teach, 
Cable in the classroom, 2003, 16-18, 2003; J. Ohler, Digital Storytelling in the Classroom: New Media Pathways to Literacy, Learning, and Creativity, Thousand Oaks-California Corwin, 2013.

[12] E. Corradini, Educational itineraries of the Italian University Museums network for the lifelong guidance to the scientific culture and method, I. Garcìa Fernandez (edited by), Proceedings Congreso Internacional Museos Universitarios, Tradicion y futuro, Madrid, December 3-5, 2014, Madrid, Università Complutense, 489- 494, 2015.

[13] E. Corradini, The Common and Interdisciplinary Itineraries of the Italian University Museum Network: a Challenge for Sharing Scientific Education, M. Haggag, N. Gesché-Koning (edited by), Proceedings of the 13th ICOM-UMAC \& 45th annual ICOM-CECA Conference, Squaring the Circle? Research, Museum, Public: a Common Engagement towards Effective Communication, Alexandria, October 9-14, 2014, Alexandria, 105-111, 2015.

[14] E. Corradini, L. Campanella, The Italian University Museums Network for the Guidance of the Scientific Culture. G. Monaco (edited by), Proceedings of the 46th annual ICOM-CECA Conference, Museum Education and Accessibility: Bridging the Gaps, Washington, D.C., September 17-21, 2015, Washington, 91-97, 2016.

[15] E. Corradini, La rete dei Musei Universitari: diffusione e contestualizzazione del patrimonio culturale degli atenei, orientamento al metodo e alla cultura scientifica, L. Magnani, L. Stagno (edited by), Atti del Convegno, Valorizzare il patrimonio culturale delle Università. Focus su arte architetture, Genova 20-21 novembre 2014, Genova, Università di Genova, 131-142, 2016.

[16] E. Corradini, Percorsi formativi della Rete dei Musei Universitari Italiani per l'orientamento permanente al metodo e alla cultura scientifica, A. Borzatti De Loewenstern, A. Roselli, E. Falchetti, (edited by), Memorie del XXIV Congresso dell'Associazione Nazionale Musei Scientifici, "Contact zone": i ruoli dei musei scientifici nella società contemporanea, Livorno 11-13 novembre 2014, Museologia Scientifica Memorie, 16, 43-47, 2017.

[17] E. Corradini, E. Endrighi, I nuovi percorsi educativi della Rete dei Musei Universitari, S. Martellos, M. Celi (a cura di), Memorie del XXVI Congresso dell'Associazione Nazionale Musei Scientifici, I musei al tempo della crisi. Problemi, soluzioni, opportunità, Trieste, 16-18 novembre 2016, Museologia Scientifica Memorie, 18, 39-44, 2019.

[18] M. C. O’ Neill, C. Dufresne -Tassé C., 2012. CECA Best practices, S. Chryssoulakis S., Bounia A., Andriopoulou D. (a cura di), Museum Education and New Media. ICOM Education 23, Ministry of Education \& Religious Affairs, Culture \& Sports, 26th Ephorate of Prehistoric and Classical Antiquities, Athens, 100-126, 2012; R. Rubiales Garcia Jurado, El Museo Contemporáneo, Catalizador de Futuro, S. Chryssoulakis , A. Bounia, D. Andriopoulou (a cura di), Museum Education and New Media. ICOM Education 23, Ministry of Education \& Religious Affairs, Culture \& Sports, $26^{\text {th }}$ Ephorate of Prehistoric and Classical Antiquities, Athens, 8-14, 2012. 